Artículo 6/2012, octubre (n. ${ }^{\circ} 138$ )

\title{
Extranjeros en los centros penitenciarios catalanes y sus trayectorias de vida
}

\author{
Manel Capdevila Capdevila y Marta Ferrer Puig (Centro de Estudios Jurídicos y Formación Especializada. \\ Departamento de Justicia. Generalitat de Cataluña)
}

Resumen: Este artículo recoge los resultados de dos investigaciones realizadas con internos extranjeros en los centros penitenciarios catalanes entre 2007 y 2010. Se describe su perfil personal, socio-familiar, penal y penitenciario, y se resumen algunos aspectos de su proyecto migratorio, su situación administrativa y su paso por prisión. Para conocer en profundidad su realidad se han realizado entrevistas semi-estructuradas sobre su capital social en los países de origen y de acogida, aspectos de su perfil criminológico y perspectivas de futuro una vez finalizada la condena. Los autores han logrado explicar la complejidad de este colectivo creando 4 grandes grupos con realidades y necesidades distintas y específicas, y han elaborado 29 recomendaciones para la mejora de todos los ámbitos de la intervención penitenciaria en este ámbito

Palabras clave: extranjeros, historias de vida, prisiones, tratamiento penitenciario

Title: Foreigners in prison in Catalonia and their life trajectories

Abstract: This article presents the results of two researches on foreign inmates in Catalan prisons between 2007 and 2010. Their personal, socio-family, criminal and prison profiles are described, and some aspects about their migratory project, their status and their stay in prison are summarized. Some semi-structured interviews have been made to find out their social capital in the countries of origin and destination, criminological aspects and future prospects after conviction. The authors have succeeded in explaining the complexity of foreign inmates creating 4 major groups with different needs and realities, and making 29 recommendations to improve all areas of correctional intervention on them.

Recepción del original: 25 junio 2012

Fecha de aceptación: 19 septiembre 2012
Sumario: 1. Introducción. 2. Objetivos. 3. Metodología. 4. Resultados: 4.1. Respecto al perfil del extranjero encarcelado. 4.2. Respecto al proceso migratorio y al apoyo social en Cataluña. 4.3. Respecto a la documentación. 4.4. Respecto a la inserción social después de la cárcel. 5. Conclusiones. 6 . Recomendaciones

\section{Introducción ${ }^{1}$}

Actualmente, en los centros penitenciarios catalanes nos encontramos con una población extranjera que representa el 45,4\% del total de los internos ${ }^{2}$. El aumento del número de personas extranjeras que se ha producido a lo largo de estos últimos años comportó que el año 2008 la Dirección General de Servicios Penitenciarios (en adelante, DGSP) planteara al Centro de Estudios Jurídicos y Formación Especializada (en adelante, CEJFE) la necesidad de conocer en profundidad las características de la población extranjera encarcelada. Diversos interrogantes concretos formaban parte de aquella demanda inicial, explícitamente recogidos en los objetivos de las dos investigaciones que se engloban en este artículo. Con todo, un tema destacado desde el principio fue la constatación de las dificultades de integración social de las personas extranjeras encarceladas una vez cumplida la pena, en el marco del complejo contexto legal que regula la extranjería en nuestro país.

La finalidad de las dos investigaciones era presentar una visión global de la realidad de los extranjeros en los centros penitenciarios de Cataluña y de sus posibilidades de futuro, apuntando recomendaciones que pudiesen ayudar a la DGSP a intervenir con mayor eficacia. Conocer las trayectorias de vida de estas personas ha permitido descubrir sus puntos fuertes y débiles, e identificar las dificultades y oportunidades que tendrán para lograr un proyecto de integración alejado del delito, ya sea en nuestro país o al retornar al suyo.

\section{Objetivos}

1. Determinar los perfiles de los presos extranjeros en Cataluña durante el periodo 2007-2008, así como sus diferencias y coincidencias según 6 áreas geográficas de procedencia: Unión Europea, resto de Europa, Magreb, resto de África, CentroSudamérica y Asia.

2. Comparar las variables personales, socio-familiares y penal-penitenciarias de la población extranjera encarcelada con las de la población penitenciaria autóctona, para encontrar similitudes y diferencias.

3. Conocer el punto de vista de los internos extranjeros respecto a la vida cotidiana en la cárcel: calidad de vida, relaciones con los funcionarios, relaciones con otros internos, valoración de los programas, expectativas tras la excarcelación, etc.

4. Describir la situación legal de los extranjeros y su evolución a nivel de documentación.

5. En función de todos los análisis anteriores, determinar qué necesidades prioritarias de los internos extranjeros deberían considerarse en la intervención penitenciaria para favorecer su calidad de vida y su reinserción social.

6. Conocer cuál es la distancia entre las expectativas de futuro que tienen a la salida de prisión y las posibilidades reales de llevarlas a cabo.

7. Conocer en profundidad los aspectos contemplados en los objetivos anteriores en relación a determinados colectivos específicos: mujeres, multirreincidentes y no documentados. 


\section{Metodología}

La investigación combina las metodologías cuantitativa y cualitativa, y parte del análisis de dos grupos de estudio diferenciados:

Grupo de estudio 1: Muestra representativa de la población extranjera que durante 2007 pasó por las prisiones catalanas. El cómputo total de personas que en algún momento del año 2007 estuvieron presas en Cataluña es de 15.317. De éstas, 6.719 eran extranjeras. Se ha hecho una muestra de 1.654 sujetos de este último conjunto, discriminando el género y respetando la distribución por áreas geográficas de procedencia. Para configurar esta muestra se extrajeron datos del sistema informático penitenciario catalán (en adelante, SIPC). El procesamiento de los datos se llevó a cabo con el programa SPSS.17.0 y se realizaron diferentes análisis de datos (correlaciones, contingencia y Chi-cuadrado, T de Student, ANOVA y análisis factorial y de fiabilidad).

Grupo de estudio 2: Extranjeros que estaban internados en algún centro penitenciario de Cataluña durante 2008. Un total de 212 internos extranjeros participaron voluntariamente en entrevistas semi-estructuradas cuyo objetivo era recabar información que no se encuentra en los expedientes. Estos 212 sujetos son distintos a los del grupo de estudio 1. Para configurar la información de este grupo se extrajeron datos de 4 fuentes: SIPC, entrevistas semiestructuradas llevadas a cabo por educadores de centros penitenciarios debidamente formados para participar como investigadores colaboradores del estudio, vaciado de los datos jurídicos de los expedientes a cargo de juristas de los centros y datos administrativos de la Subdelegación del Gobierno de España en Barcelona respecto a su situación legal en nuestro país. Las entrevistas fueron grabadas en audio y transcritas en papel utilizando el software libre F4 versión 3.1.0. Para el análisis en profundidad de las entrevistas se ha usado el programa de análisis cualitativo de datos contextuales ATLAS/ti 6.2.

\section{Resultados}

\subsection{Respecto al perfil del extranjero encarcelado}

En el año 2007, en relación al género, el 93,2\% de los internos extranjeros eran hombres (proporción muy similar a la de los autóctonos que era del 92,6\%). La media de edad de los extranjeros tanto en relación al primer ingreso en la cárcel (27,3 años) como en la edad de entrada del ingreso base, es decir, la sanción más grave que estaba cumpliendo en 2007 (31,3 años), era también similar a la de los últimos datos disponibles en relación a población española (resultados de 2002) 3 $^{3}$ En cuanto a la salud, el $63,1 \%$ de internos extranjeros tenía la percepción de que ésta había cambiado desde que ingresaron en prisión. De este grupo, más de la mitad consideraba que había mejorado, y lo atribuyeron a llevar una vida ordenada que no habían podido tener fuera. El 80,7\% manifestó haberse sentido triste por estar encarcelados, aunque no hay constancia de autolesiones graves ni tentativas de suicidio. El 31,1\% de los extranjeros entrevistados reconocieron tener problemas con las drogas. De este grupo, un 75,8\% afirmó haber abusado gravemente de ellas y un $59,4 \%$ pensaban que el consumo estaba interfiriendo de forma moderada en su vida. Cannabis, alcohol y cocaína son las drogas de mayor consumo.

Los extranjeros primarios penitenciarios (que ingresan por primera vez en la cárcel en Cataluña) suponían el 75\% de los extranjeros encarcelados en el año 2007 (con un aumento del $23,2 \%$ respecto al año 2002). El porcentaje de preventivos entre los extranjeros encarcelados era del 35,6\% (frente al 14,1\% de los autóctonos). Los delitos principales por los cuales se encontraban ingresados en prisión eran los relacionados con el tráfico de drogas $(35,7 \%)$, seguido de los delitos contra la propiedad $(32,6 \%)$, contra las personas $(14,3 \%)$, otros delitos $(11,9 \%)$ y, por último, contra la libertad sexual (5,5\%). En 2007 aumentó significativamente el uso de la violencia en el delito cometido por los extranjeros (32,2\% en el año 2007 frente al 8,2\% del año 2002).

En relación al régimen penitenciario, disminuyó el porcentaje de permisos ordinarios concedidos a los extranjeros en el intervalo de tiempo entre el año 2002 y el año 2007 (una disminución de 15,5 puntos: del $41 \%$ en el año 2002 al 25,5\% en el año 2007) y también el porcentaje de salidas programadas (disminuyó 4,8 puntos: del 15\% en el año 2002 al 10,2\% en el 2007).

El número de incidentes, faltas y sanciones entre los extranjeros en el intervalo estudiado no ha variado. La adaptación de los extranjeros a la normativa y al régimen penitenciario es mejor que la que tienen los internos autóctonos si tomamos como indicadores el número de incidentes ( 0,5 incidentes de media para los extranjeros frente al 1,6 de media de los españoles), el número de faltas (1,5 de media para los extranjeros frente al 3,4 de media de los españoles) y el número de sanciones (1,1 de media para los extranjeros frente al 2,7 de los españoles).

Tres de cada cuatro extranjeros encarcelados señalaban no querer que su consulado fuese informado de su presencia en un centro penitenciario del país $(76,4 \%)$. Para entender este dato hay que saber que la regularización del extranjero implica (en la mayoría de casos) gestiones previas imprescindibles con el consulado.

\subsection{Respecto al proceso migratorio y al apoyo social en Cataluña} En cuanto a las características del proceso migratorio, se dan idénticas proporciones en las respuestas de los internos extranjeros y en las de la población extranjera en general. En concreto: a) el motivo de salida de su país de origen es mejorar su calidad de vida (un 75,8\%); b) los factores y agentes de arrastre hacia España son los parientes, principalmente hermanos y amigos (que suman un 44,5\%); c) cuentan con capital social en España previo a su llegada ${ }^{4}$, en especial tener familia $(25,7 \%)$; d ) vienen con la familia $(25 \%)$.

En cambio hemos encontrado diferencias respecto a: $f$ ) la forma de viajar (vienen menos directamente desde su país de origen que el resto: $36,9 \%$ de los internos frente al $87 \%$ de la población extranjera en general); g) la falta de documentación requerida a la entrada cuando ésta es necesaria en forma de visado $(82,2 \%$ entre los extranjeros encarcelados frente al 19\% de la población extranjera en general). Una última observación: h) una tercera parte de los internos extranjeros fueron detenidos nada más llegar a España.

En cuanto a las relaciones familiares, según nuestro estudio dos terceras partes de los extranjeros encarcelados $(66,3 \%)$ tenían familiares aquí, en España, y mantenían contacto con ellos. Datos de los expedientes penitenciarios revelan que un $44,9 \%$ recibieron bastantes visitas (semanalmente), mientras que un $17,6 \%$ no recibió ninguna. La mayoría de estas visitas son familiares $(64,0 \%)$; el resto son amigos $(15,1 \%)$ y otros $(20,9 \%)$. Un 39\% reconoció no tener pareja en ese momento. De los que sí tenían, el 51\% hablaba de relación estable. Un 27,8\% de los presos extranjeros no tenía a nadie que pudiera ocuparse de sus asuntos fuera de la cárcel. Un 34\% no sabía nada del país en que se encontraban, ya que fueron encarcelados en cuanto llegaron.

\subsection{Respecto a la documentación}

En la mitad de los casos del estudio (48,5\%), no constaba ningún tipo de documentación en el expediente del centro penitenciario. Un 40,6\% de los presos extranjeros no aparecían registrados en 
la Subdelegación del Gobierno de España en Barcelona; es decir, no constaba ni el NIE (número de identificación del extranjero). De este porcentaje hay que descontar el $10,4 \%$ que eran ciudadanos de países de la Unión Europea que no lo necesitan como requisito para los trámites documentales. Un $65,3 \%$ de los entrevistados dijo haberse empadronado; 68,6\% decían tener tarjeta sanitaria; un $43 \%$ manifestaron que tenían permiso de residencia; un $36,4 \%$ dijeron tener permiso de trabajo (estos dos últimos porcentajes se ajustan bastante a los datos que figuran en la Subdelegación del Gobierno); un 16,9\% manifestaron que tenían contrato laboral; un $17,9 \%$ tenía abierto un expediente de expulsión en la Subdelegación del Gobierno.

Las mujeres están peor documentadas. Tres datos sustentan esta afirmación: un 51,6\% no tenían NIE (número de identificación de extranjeros) en la Subdelegación del Gobierno, un 44,3\% no habían tramitado la tarjeta sanitaria y un 53\% carecían de permiso de trabajo en España.

\subsection{Respecto a la inserción social después de la cárcel}

De las 371 variables informadas a partir de las diferentes fuentes de la investigación, se han agrupado en grandes factores las que han resultado más relevantes para describir las perspectivas de inserción social de los internos extranjeros. Los factores que en nuestra investigación clasifican mejor a los extranjeros encarcelados son: a) la documentación, b) el comportamiento disciplinario, c) el proceso de rehabilitación, d) los antecedentes penitenciarios y e) la voluntad de retorno. Otros factores que también ayudan a esta clasificación, aunque sin tanta fuerza son: f) el proceso migratorio, g) el capital social y h) las relaciones en la cárcel. En algunos de estos factores profundizamos en el análisis cualitativo.

Estos factores nos han permitido establecer diferentes grupos de extranjeros que, sin constituir una clasificación cerrada, tienen importantes características diferenciadoras. Se trata de una aproximación explicativa que parte del hecho de que no todos los extranjeros tienen las mismas posibilidades ni las mismas probabilidades de inserción social después de cumplir la pena. Desde esta perspectiva, se han identificado cuatro grandes grupos que presentan perspectivas de inserción muy diferentes en función de los factores comentados. Estos grupos ayudan a constatar la necesidad de diferentes tipos de intervención por parte de la institución penitenciaria. El porcentaje de cada grupo nos da una aproximación de su relevancia en el conjunto de internos penitenciarios extranjeros (gráfico 1).

El grupo 1 (desarraigados) es el que tiene el peor pronóstico de inserción social a la salida de la cárcel. Corresponde aproxi- madamente al $20 \%$ de los entrevistados y como principales características se pueden destacar que son extranjeros que no quieren retornar a su país, no han tenido nunca ningún tipo de documentación, no disponen de capital social aquí y no tienen proyecto migratorio definido. Con los internos que forman parte de este grupo creemos que, desde el ámbito penitenciario, hay que trabajar desde el primer día para que acepten el retorno voluntario a su país, dadas las pocas posibilidades que tienen de quedarse en España con garantías de no caer en la exclusión social a causa, fundamentalmente, de la imposibilidad de obtener la regularización y/o por la falta de capital social aquí. El grupo de expertos que han participado en la investigación defienden la sustitución de la segunda parte de la condena por la expulsión y perseguir de manera más decidida la aplicación de esta alternativa. No obstante, este proceso, para contar con la implicación del interno y para garantizar un buen final, tendría que ir acompañado de medidas de apoyo sociolaboral en el país de origen. Mientras sigan en prisión se debe intentar potenciar su participación en todas aquellas actividades que puedan mejorar su reinserción allá donde ésta se tenga que producir.

El grupo 2 (refractarios) incluye aproximadamente el 30\% de los casos entrevistados. Estos extranjeros tampoco quieren irse del país pero, a diferencia del grupo anterior, sí que han tenido o tienen documentación regularizada, disponen de capital social aquí y llegaron con un proyecto migratorio, la mayoría, el de sus padres. Los extranjeros de este grupo son, de media, más jóvenes que los otros tres, tienen más a menudo antecedentes penitenciarios y reconocen más problemas de toxicomanía. A su vez, dentro de la cárcel su comportamiento es disruptivo. El pronóstico de inserción social a la salida es muy incierto. El tipo de problemática personal de los extranjeros que forman parte de este grupo implica un trabajo con intervenciones muy individualizadas centradas en los factores de perfil criminológico que presentan. Hay una falta de expectativas y posibilidades de regularizar su situación administrativa en España por la presencia de antecedentes penales, a la cual hay que sumar la posibilidad de reincidencia en el delito a causa de su problemática. Sin un trabajo sobre estas dificultades personales y sin el apoyo de su capital social será muy difícil lograr objetivos de inserción. El trabajo en la cárcel tendría que dirigirse a conseguir que el máximo número de sujetos posibles se incorporen al grupo 3, superando las dificultades personales que se lo impidan.

En el grupo 3 (arraigados) también encontramos otro 30\% de los casos entrevistados. Las diferencias con el grupo anterior se encuentran en su perfil penal y penitenciario: no tienen antecedentes penales conocidos, presentan un buen comportamiento dentro de

Gráfico 1. Pronóstico de inserción social de los extranjeros al salir de prisión

Mal pronóstico

Buen pronóstico

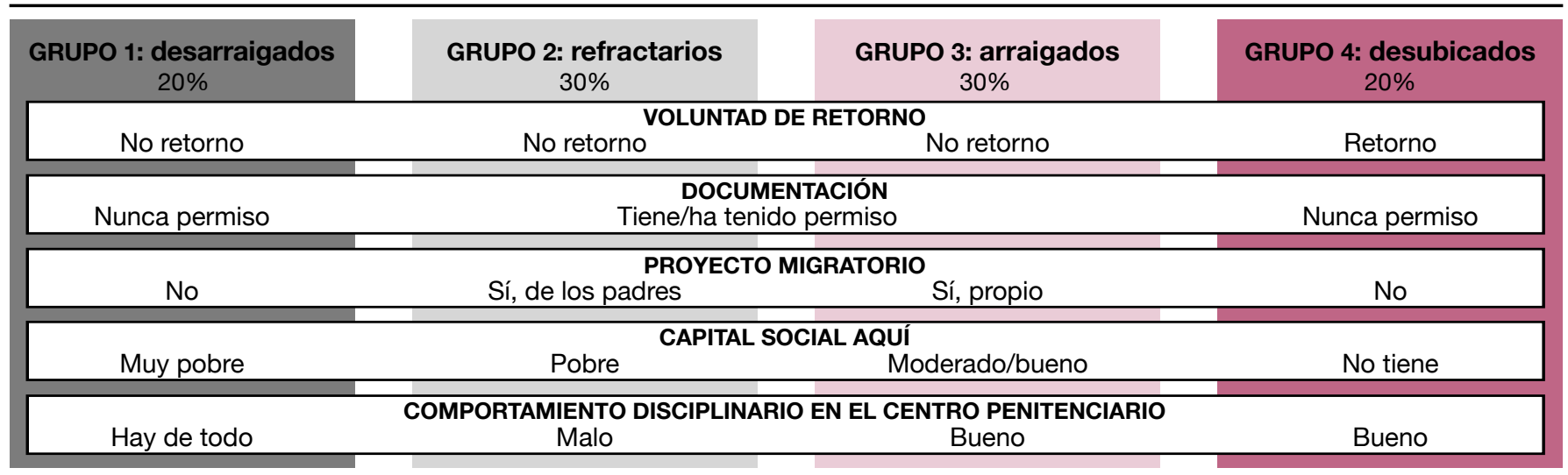


la cárcel y no reconocen problemas de abuso de drogas. El principal obstáculo que tienen que superar es la renovación de los permisos de residencia y trabajo a causa de los antecedentes penales. Con este grupo creemos que se debe trabajar para que consoliden su capital social y sus posibilidades de inclusión social a través de la formación y el trabajo. Dado que la mayoría trabajan a través del CIRE (Centro de iniciativas para la reinserción), se tendría que fomentar lo más rápido posible el acceso a tercer grado penitenciario, la aplicación del artículo 86.4 del reglamento penitenciario y el acceso a la libertad condicional. Los profesionales de tratamiento de los centros penitenciarios tendrían que realizar todos los esfuerzos posibles para lograr los objetivos de normalización social y regularización de las personas integradas en este grupo a su salida.

El grupo 4 (desubicados) constituye el 20\% de los entrevistados. Es el único grupo de extranjeros que manifiesta en la entrevista su voluntad de retorno. No disponen ni han dispuesto nunca de documentación española (empadronamiento, tarjeta sanitaria, permiso de residencia y/o trabajo). No disponen de capital social aquí ni llegaron con un proyecto migratorio. No tienen demasiados problemas disciplinarios dentro de la cárcel. El pronóstico de inserción social de este grupo a su salida de la prisión es moderadamente optimista si bien se focaliza en los países de origen. Entendemos que el trabajo con este grupo pasa por resolver de manera ágil el retorno a su país en las circunstancias y condiciones que cada caso requiera, explotando al máximo las posibilidades que otorga la ley. Cuanto más eficiente y rápida sea la tramitación del retorno más posibilidades de éxito y satisfacción para todas las partes. En caso contrario, el peligro es que los extranjeros encarcelados recurran a otras estrategias que generen nuevos problemas de exclusión social.

A menudo la realidad que pensamos que se encontrará el extranjero de cada grupo al salir del centro penitenciario entra en conflicto con sus intereses y su voluntad de quedarse aquí a cualquier precio. Entendemos que las propuestas de solución tendrían que pasar por acercar estos intereses a la viabilidad real de integración en la sociedad española o en el país de origen. A pesar de haber acabado en la cárcel, la mitad de los presos extranjeros creen que ha valido la pena haber emigrado, y un $84 \%$ manifiesta como principal deseo al salir el poder disfrutar de una vida normalizada. Solamente el 7,9\% aceptaría sustituir la pena por la expulsión del país y solo un 3,5\% aceptaría cumplir la pena de prisión en su país.

\section{Conclusiones}

La primera conclusión que querríamos destacar hace referencia a la falta de información que tienen los extranjeros encarcelados en relación a las especificidades de su condición de extranjeros y respecto a sus perspectivas de futuro. En muchos de sus discursos ha quedado demostrado su desconocimiento respecto a la realidad en la que se encuentran inmersos tanto en relación a su salida de prisión como, en general, en relación a su situación en nuestro país y como ésta afecta a las posibilidades de la salida. Los extranjeros se encuentran muy desorientados y no saben a qué atenerse. Probablemente, en buena parte fruto de esta falta de información, toman decisiones poco adecuadas a sus oportunidades o dejan de tomar otras que les convendrían. Las respuestas que dan a las preguntas sobre intereses y perspectivas de futuro muestran muchas veces desorientación respecto a lo que esperan, inconsciencia en las actuaciones que emprenden e incoherencia respecto a lo que demandan, o resignación pesimista ante las posibilidades de lograrlo. Esta toma de decisiones errónea puede agravar aún más su situación en el momento de la salida y hacer inviable su reinserción social.

Esta conclusión nos lleva a plantear como propuesta la necesidad de realizar un trabajo riguroso de acompañamiento del extranjero encarcelado, conducido por los profesionales de los centros penitenciarios o por otros expertos. El hacerlo puede incidir de manera clara y exitosa en una preparación coherente de las personas extranjeras encarceladas para su salida de prisión.

En este sentido, la principal conclusión de este estudio es la identificación de los dos elementos clave que permiten definir unas perspectivas de futuro pesimistas, inciertas u optimistas en relación a las posibilidades de los extranjeros encarcelados una vez salgan de prisión. Estos dos elementos clave para pronosticar estas perspectivas de futuro son: 1) la distancia existente entre las expectativas de futuro y las posibilidades reales de lograrlas y 2) la propia voluntad de la persona.

Si la distancia entre las expectativas y las posibilidades reales de lograrlas es corta, podríamos hablar de un buen pronóstico. Si la distancia es grande, seguramente hablaríamos de un mal pronóstico. Del mismo modo opera la realidad de la propia voluntad del interno extranjero. Si esta voluntad es férrea para salir adelante a pesar de las dificultades y de no delinquir nuevamente, hablaríamos de un buen pronóstico. Si esa voluntad es frágil, hablaríamos de un mal pronóstico.

Las perspectivas de futuro más pesimistas las tienen los extranjeros encarcelados para los cuales la distancia entre lo que quieren tener y hacer a la salida de prisión y las posibilidades reales de conseguirlo de manera legal es muy grande. Además, su voluntad para no volver a delinquir es muy frágil ya que no expresan estrategias claras y realistas para afrontar las dificultades que se pueden encontrar por el camino en su intento de lograrlo ${ }^{5}$.

Las perspectivas más optimistas las tienen aquellas personas para las cuales la distancia entre lo que quieren tener y hacer a la salida de prisión es muy ajustada a sus posibilidades de conseguirlo, a la vez que muestran una voluntad férrea para hacerlo sin delinquir, expresando estrategias alternativas ${ }^{6}$.

En las perspectivas inciertas se encuentran aquellos discursos en los cuales, o bien hay mucha distancia entre lo que quieren y lo que pueden lograr en la realidad pero muestran una voluntad férrea para conseguirlo sin delinquir, o bien la distancia es corta y realista pero su voluntad es frágil y no se conecta a unas estrategias claras que les permitan afrontar la salida de prisión con garantías?.

\section{Recomendaciones}

El estudio concluye con 29 recomendaciones agrupadas en 7 grandes apartados que se proponen como herramientas para la planificación de la intervención con los internos extranjeros y para la mejora de su reinserción social. Para llegar a estas 29 recomendaciones los autores del informe han tenido en cuenta los resultados de la investigación en todos sus apartados, la opinión de la comisión de expertos que ha asesorado al CEJFE a lo largo de su elaboración y las recomendaciones que para las cárceles europeas se hacen en la bibliografía internacional ${ }^{8}$. 


\title{
Referencias (versión digital)
}

\begin{abstract}
Notas
${ }^{1}$ Las investigaciones a las que se refiere el artículo son: Extranjeros en las cárceles catalanas (2010) y Trayectorias de vida de los extranjeros encarcelados (2011). Área de Investigación y Formación Social y Criminológica. Barcelona. CEJFE. Pendientes de publicación en libro Col-lecció Justícia i Societat. Están publicadas en web en la siguiente dirección www.gencat.cat/justicia/investigacions

${ }^{2}$ Datos correspondientes a la semana del 15 al 21 de agosto de 2011, facilitadas por el Área de Planificación y Proyectos Estratégicos dependiente de la DGSP del Departamento de Justicia de la Generalitat de Cataluña.
\end{abstract}

${ }^{3}$ Los datos de los extranjeros y de los autóctonos correspondientes al año 2002 se han extraído de la investigación Tasa de reincidencia penitenciaria 2008, editada por el CEJFE en el año 2009. Publicación en línea: http://gencat.cat/justicia/cejfe

${ }^{4}$ Cuando hablamos de capital social nos referimos a las redes sociales personales: a quién conocen, recursos para pedir ayuda u obtener información, cómo se relacionan y cómo colaboran entre ellos.

${ }^{5}$ Un ejemplo de perspectivas pesimistas sería el caso 4004: Llega hace 6 años en varios vehículos caravana que utilizan de domicilio itinerante. En total son 14 parientes los que viajan, entre los que se encuentra su madre, actualmente en prisión. Sus fuentes de ingresos son la economía informal y algunas actividades disociales. Ingresa en un centro de menores del que se fuga a los dos días. Tiene problemas de toxicomanía y no ve claro poder dejarlo. En prisión no trabaja y realiza aquellas actividades que el tutor le programa como obligatorias para poder acceder a beneficios penitenciarios. No tiene claro dónde se va a quedar cuando salga y no le gusta la sociedad de acogida.

Extracto de la entrevista: "...porque antes yo tomaba mucha droga ino?...estaba muy... muy débil, muy flaco, no comía, no podía comer. He mejorado mucho eso. Y ya de dejar... si la droga... esto ya...//... Lo que más me gusta de Cataluña es la playa ila gente? los catalanes son un poco racistas, mal. Con la gente que no es de aquí, pues bien....//...Pues mira, eso es una buena pregunta. Lo primero papeles. Lo segundo una faena y después ya...” [4004; Bosnia y Herzegovina, 23 años] Cumple 3,2 años de pena. Siete causas acumuladas. Lleva tres años en prisión. Actualmente evadido de un permiso de fin de semana (agosto 2010).

${ }^{6}$ Un ejemplo de estas perspectivas optimistas es el caso 4013. Llega directamente de Argentina al aeropuerto de Barajas con todos sus ahorros, en la época del corralito argentino. Pese a entrar con el visado de turista, al cabo de 10 días ya obtiene trabajo sin contrato en el sector de la hostelería y poco a poco se establece hasta regularizar su situación administrativa. Actualmente tiene permiso permanente y sabe explicar todos los trámites a realizar para obtener y mantener la documentación. Tiene una nueva familia adquirida al casarse en segundas nupcias con una española con 2 hijos. En prisión ha trabajado y ha realizado todo tipo de cursos de formación. Es primario en su ingreso penitenciario y no tiene ningún expediente disciplinario. Pasó a tercer grado y obtiene finalmente la libertad condicional sin más incidencias.

Extracto de la entrevista: “...llegaron rumores de que aqui, en España, se pagaba bien mi trabajo y decidí venir aquí...// ...Más que nada por el habla, somos países hermanos... y bueno, los tratados también me convenian, porque hay tratados especiales ino? entre Argentina y España que no los tienen otros países...//...Si, el SAC (tratamiento para delitos sexuales)...//...Me, me ha gustado y me ha...bueno, me ha hecho recapacitar muchas cosas...//...A, ya, pero no. Solamente intentar recuperar mi vida anterior, que lo estoy baciendo, y que se valoren un poco también las cosas a nivel más individual, que se generaliza mucho... Y que bueno, ya prácticamente me queda poco y...//...Pero que bueno, quien las hace las paga, yo estoy de acuerdo, ino? Porque quien comete un delito, a lo hecho pecho. Pero a veces hay casos que no, que no hay que generalizar tanto, ino?...//... Bueno, que no son deseos tampoco, son opiniones personales. (no se entiende). que volver a recuperar mi vida y que no me queden secuelas, que no me están quedando porque de eso me he ocupado yo y bueno... Casarme, que me caso el mes que viene y nada más, trabajar y disfrutar. Y a recuperar los años perdidos. Salud también. Salud, dinero y amor, como dice la canción, es lo que deseo, sí. Y ya está...” [4013; Argentina, 44 años]. Cumple 7 años de pena. Única causa. Actualmente en libertad sin incidencias conocidas.

${ }^{7}$ Un ejemplo de estas perspectivas inciertas es el caso 3004. Una mujer búlgara de clase media que viene para mejorar su situación económica. Tiene claro que para conseguirlo la prostitución es una manera rápida y frecuenta círculos de paisanos que se mueven en este mundo. Se casa con un español para conseguir papeles, pero su pareja real es una persona fuertemente conflictiva y drogodependiente que se encuentra actualmente encarcelado en una prisión española. Es reincidente penitenciaria. Cuando sale de prisión se trae a su hijo y a su madre de Bulgaria, y cuando vuelve a entrar se van nuevamente a su país. Estudia en prisión una carrera universitaria. No consta problemática toxicológica. Le quedan bastantes años de condena y otras causas pendientes. Su intención es quedarse aquí al salir de prisión, pero se muestra receptiva a marcharse antes si ello le permite estar cerca de su hijo en Bulgaria.

Extracto de la entrevista: "mi familia está económicamente situado como vuestros, una familia de clase media, ni alta ni baja. Aunque mi madre, son con estudios universitarios los dos de mis padres, pero el salario en Bulgaria no, no permite para muchas cosas...//...Es una relación amistosa que tenemos. El chico me ha ayudado muchisimo, no tiene nada que ver ni con esta causa, ni con mafia ni con nada. Es un chico que me ha ayudado muchisimo con la documentación porque yo la necesitaba. Se ofreció voluntario, no hay nada de "trapicheos" de yo te pago por la documentación, no es porque simplemente esa persona ha querido ayudarme para que no tenga problemas con la documentación...//...en el momento cuando sucedieron los hechos pues sí, necesitaba bastante con urgencia el dinero. Para cosas mi pareja tuvo algunos problemas con, con cierto de tomar cocaína o juegos de azar y entonces pues se acumularon deudas.. //.... Hombre, es que tengo un hijo, tengo familia, no puedo verlo, $m m m m$... vamos que han pasado un montón de cosas y me ha perjudicado muchísimo a esto. Y claro, yo prefiero estar con mi bijo...// ...Quedarme en España obviamente porque es que llevo muchos años aquí. Volver a Bulgaria es empezar como, que empecé de aquí, de cero. Entonces, pues arreglarme la residencia y donde lo dejé. Si salgo de aquí con estudios, bien y si me faltan pues acabarlos en la calle buscando trabajo que siempre me ha gustado, pues, al final y ya está, no más ni menos. Bien pagado, pues poder, como todo el mundo, cogerme una casa si es posible, pagármela a plazos, que no sea de alquiler, porque..." [3004; Bulgaria, 30 años]. 10 años de condena (2 cumplidos en el momento de la entrevista) Causas pendientes. Actualmente sigue cumpliendo aquí sin incidencias conocidas.

${ }^{8}$ Van Kalmthout, A.; Hofstee-van der Meulen, F.; Dünkel, F. (2007). “Comparative Overview, Conclusions and Recommendations”. En Foreigners in European Prisions, volumen I, Págs. 7-90. 


\section{Bibliografía:}

ABDELOUAHED ALLAOUI, M'hamed (2008). "Els joves d'origen immigrant en el si de les societats d'acollida. Una pertinença diferent”. EnInf@ncia, butlletí dels professionals de la infància i l'adolescència. Barcelona: Direcció General d'Atenció a la Infància i l'Adolescència, septiembre 2008. Págs. 49 y ss.

ACHOTEGUI LOIZATE, Joseba (2006). "Estrés limite y salud mental: el síndrome del inmigrante con estrés crónico y múltiple (síndrome de Ulises)". En Migraciones, núm 19. Madrid: Instituto Universitario de estudios sobre inmigraciones. Universidad Pontificia Comillas, junio 2006. Págs. 59-85.

ACHOTEGUI, J (1995). “Migrar: duelo y dolor”. En El viejo Topo núm. 90. Barcelona. Págs. 31-38.

AJA, Eliseo; NADAL, Mònica (dir.) (2004). La immigració a Catalunya avui. Anuari 2003. Barcelona: Fundació Jaume Bofill. Editorial Mediterrània (Col. Polítiques, 41). Págs. 351.

AJENJO, M.; et al. (2008). Les condicions de vida de la població immigrada a Catalunya. Barcelona: Fundació Jaume Bofill. Editorial Mediterrània (Col. Polítiques; 63). Págs. 193.

ALCALDE CAMPOS, Rosalina (2008). "Els reagrupaments familiars a Catalunya: evolució i característiques dels fluxos de reagrupament familiar”.En Larios, M. Jesús; Nadal, Mònica (dir.). L'estat de la immigració a Catalunya. Anuari 2007. Barcelona: Ed. Mediterrània. Págs. 117-139. (edición electrónica) http://www.migracat.cat/document/443de8b787bed01.pdf [consultado: 1 de junio de 2009].

ALEGRE, M. A.; RICARD, B.; GONZÁLEZ, S. (2007). Els sistemes educatius als països d'origen de l'alumnat immigrat. Una aproximació. Barcelona: Fundació Jaume Bofill (Col. Informes Breus Immigració; 8) (edición electrónica) http://www.fbofill.cat/intra/fbofill/ documents/publicacions/459.pdf [consultado: 7 de agosto de 2008].

APARICIO, Rosa; TORNOS, A. (2003). Buenas prácticas de integración de los inmigrantes. Estudio exploratorio en las comunidades de Madrid, Cataluña, Andalucía y Comunidad de Múrcia. Madrid: IMSERSO (edición electrónica) http://www.seg-social.es/imserso/ investigacion/estud2004/bpintinmig.pdf [consultado: 7 de agosto de 2008].

APARICIO, R; TORNOS, A. (2005). Las redes sociales de los inmigrantes extranjeros en España. Madrid: Documentos del Observatorio Permanente de la Inmigración, Ministerio de Trabajo y Asuntos Sociales. 152 Págs.

ARTAL RODRIGUEZ, Carmen; PASCUAL DE SANS, Àngels, SOLANA SOLANA, Miguel (2006). Trajectòries migratòries de la població estrangera a Catalunya. Les poblacions marroquina, equatoriana i pakistanesa. Bellaterra: Grup de Recerca sobre Immigracions, Universitat Autònoma de Barcelona. (edición electrónica) http://www.gencat.net/benestar/societat/convivencia/recursos/ publicacions/index.htm [consultado: 4 de agosto de 2008].

AUBARELL, Gemma (2000). "Una propuesta de recorrido bibliográfico por las migraciones femeninas en España". En Papers, Revista de sociología, núm. 60. Bellaterra: Universitat Autònoma de Barcelona. Págs. 391-413. (edición electrónica) http://selene.uab.es/depsociologia/revista.htm [consultado: 4 de julio de 2009].

AYUSO VIVANCOS, Alejandro (2003). Visión crítica de la reeducación penitenciaria en España. Valencia: Nau Llibres. 135 Págs.BALADO RUIZ-GALLEGOS, Manuel (dir.) (2008). Inmigración, estado y derecho. Perspectivas desde el siglo XXI. Barcelona: Bosch. 1.190 Págs.

BENITO, F.; GIL, M.; VICENTE, M. A. (2007). "Efectos aparejados por el hecho de compartir celda". En Revista de Estudios Penitenciarios, núm. 253. Págs. 9-29.

BENTHAM, J.; FOUCAULT, M. (1979). El ojo del poder. El panóptico. Madrid: La piqueta. 145 Págs.

BESALÚ, X. (2008). “Educación, inmigración y diversidad cultural”. En Cuadernos de pedagogía, núm. 380, junio 2008. Págs. 84-90.

BOWLBY,J. (1985). La separación afectiva. Paidós. Biblioteca de Psicologia profunda; 49. 444 Págs.

CAPDEVILA,M.; FERRER,M (2009). Taxa de reincidència penitenciària 2008. Barcelona: CEJFE. [Informe en pdf]. http:// www.gencat.cat/justicia/cejfe

CAPDEVILA,M.; FERRER,M (2008). Salut mental i execució penal. Barcelona: CEJFE. Collecció Justícia i Societat, núm. 29.316 Págs.CARRASCOSA, J.; DURAN, A.; CARRILlO, B. (2008). Curso de nacionalidad y extranjería. 2a ed. Madrid: Colex (Col. Derecho de la globalización; 11). 526 Págs.

CASTLES, Stephen (2004). "Por qué fracasan las políticas migratorias?”. En Migraciones, núm 15. Madrid: Instituto Universitario de Estudios sobre Inmigraciones, Universidad Pontificia de Comillas, Junio 2004. Págs. 147-184.

CENTRE D’ESTUDIS D’OPINIÓ. Departament d'Economia i Finances. Generalitat de Catalunya. Òmnibus julio 2007 (estudi REO 390) y Òmnibus julio 2008 (estudi REO 440) (edición electrónica) http://www.gencat.cat/economia/ceo/ [consultado: 17 de julio de 2008].

\section{CENTRE D'ESTUDIS JURÍDICS I FORMACIÓ ESPECIALITZADA (CEJFE):}

INVESBREU 18. Avaluació de l'efectivitat dels programes de tractament amb delinqüents a Europa. Barcelona: Centre d'Estudis Jurídics i Formació Especialitzada (CEJFE), enero 2001.

JUSTIDATA 49. La llibertat condicional a Catalunya (periode 2002-2006). Barcelona: Abril 2009

JUSTIDATA 45. L'opinió de les dones recluses a Catalunya sobre l'encarcerament. Barcelona: CEJFE, noviembre 2006.

JUSTIDATA 44. Evolució de la població penitenciària a Catalunya $i$ al conjunt de l'Estat espanyol 1999-2005. Barcelona: CEJFE, mayo 2006.

JUSTIDATA 41. Els estrangers a les presons de Catalunya (periode 2000-2004). Barcelona: CEJFE, junio 2005.

JUSTIDATA 33. La llibertat condicional a Catalunya en els darrers 5 anys (1997-2001). Barcelona: CEJFE, noviembre 2002.

JUSTIDATA 29. Evolució de la població penitenciària a Catalunya des de l'aplicació del Codi penal de 1995. Barcelona: CEJFE, febrero 2002.

JUSTIDATA 26. Els estrangers a les presons de Catalunya 1995-1999. Barcelona: CEJFE, diciembre 2000. 
JUSTIDATA 19. Evolució de la població encarcerada per delictes contra la llibertat sexual. Catalunya mayo 1996 - diciembre 1997. Barcelona: CEJFE, diciembre 1998.

JUSTIDATA 18. Evolució de la població encarcerada per delictes contra les persones. Catalunya mayo 1996 - diciembre 1997. Barcelona: CEJFE, noviembre 1998.

JUSTIDATA 17. Evolució de la població encarcerada per delictes contra la salut pública i contra la seguretat del trànsit. Catalunya mayo 1996 - diciembre 1997. Barcelona: CEJFE, septiembre 1998.

JUSTIDATA 16. Evolució de la població encarcerada per delictes contra el patrimoni i contra l'ordre socioeconòmic. Catalunya mayo 1996 - diciembre 1997. Barcelona: CEJFE, mayo 1998.

JUSTIDATA 15. Evolució de la població penitenciària. Catalunya abril 1993 - octubre 1997. Barcelona: CEJFE, noviembre 1997.

JUSTIDATA 1. Evolució de la població penitenciària. Catalunya 1985 - 1991. Barcelona: CEJFE, julio 1992.

CENTRO DE INVESTIGACIONES SOCIOLÓGICAS. Barómetros de opinión. Consulta en web els estudis del gener de 2001 fins al julio de 2009. http://www.cis.es/ [consultado: 17 de julio de 2008 y 1 de septiembre de 2009].

CEP y Reclasering Nederland (2008). "Els estrangers a les presons europees: de les bones pràctiques a les bones polítiques". En las jornadas organizadas el 16 y 17 de octubre de 2008 por el Àrea Internacional de Reclasering Nederland, Ministerio de Justicia de Holanda, Prisoners Aroad y Prison Watch.

CEREZO DOMINGUEZ, Ana Isabel; GARCIA ESPAÑA, Elisa (coord.) (2007). La prisión en España: una perspectiva criminológica. Granada: Comares. 419 Págs.

CIRE. Servicio de Extanjería. Preguntas más frecuentes. Consulta en línea. http://europa-oaid.uab.es/proexit/borsatreball/ estrangeriaFAQ.html [última visita: 29 de marzo de 2010]

CITE (2008). Jornades de reflexió. Dones immigrades: treball i sindicat. Barcelona: Dianagraf. 163 Págs.

CONSELL D'EUROPA (1984). Recommendation No. R (84) 12 of the Committee of Ministers to member states concerning foreign prisoners. 4 Págs. https://wcd.coe.int/com.instranet.InstraServlet? command=com.instranet.CmdBlobGet\&InstranetImage $=603781 \&$ SecMode $=1 \&$ DocId $=682798 \&$ Usage $=2$ [consultado: 12 de agosto de 2009].

CONSELL D'EUROPA (2008). Estadístiques Penals Anuals del Consell d'Europa SPACE I i SPACE II. Años 1997 a 2008. http:// www.coe.int/T/F/Affaires_juridiques/Coop\%E9ration_juridique/Emprisonnement_et_alternatives/Statistiques_SPACE_I/ [consultado: 29 de octubre de 2008 y julio de 2009].

CORONA, Víctor (2007). Ser latino a l'escola catalana: reflexions al voltant de les identitats, l'aprenentatge de les llengües $i$ el fracàs escolar. Barcelona: Observatori de la Migració a Catalunya (Informe; 10). 107 Págs. http://www.migracat.cat/document/1bf19907a1036d9.pdf [consultado: 1 de junio de 2009]

DE LA CUESTA, J.L. (2007). “Spain”. En Foreigners in European Prisons, volumen II. Págs. 753-783.

DEPARTAMENT DE JUSTÍCIA, Informació estadística bàsica núm. 11, diciembre 2009; núm. 10, julio 2009; núm. 8, julio 2008; núm. 1, marzo 2005. Generalitat de Catalunya. www.gencat.cat/justicia [consultado: 27 de octubre de 2008, 29 de septiembre de 2009 y 10 de marzo de 2010]

DEPARTAMENT DE JUSTÍCIA. Estrangers, descriptors estadístics. Núm.12. Generalitat de Catalunya. Àrea de Planificació i Projectes Estratègics. Diciembre 2007. Págs. 62. www.gencat.cat/justicia [consultado: 27 de octubre de 2008].

DEPARTAMENT DE JUSTÍCIA. Memòria del Departament de Justícia. 2007. Generalitat de Catalunya, septiembre 2008. www.gencat.cat/ justicia/ [consultado: 27 de octubre de 2008].

DIAZ GARCIA CONLLEDO, Miguel (dir.) (2007). Protección y expulsión de extranjeros en derecho penal. Madrid: La Ley. 758 Págs.

DÍEZ NICOLAS, Juan (2004). Las dos caras de la inmigración. Madrid: Ministerio de Trabajo y Asuntos Sociales. http://www.segsocial.es/imserso/investigacion/estud2004/inmigespana.pdf [consultado: 7 de agosto de 2008]

DÍEZ RIPOLLÉS, Jose Luís; GARCIA ESPAÑA, E. (dirs.) (2009). Encuesta a víctimas en España. Málaga: Ed. Fundación Cajasol e Instituto Andaluz Interuniversitario de Criminología. 205 Págs.

DÍEZ RIPOLLÉS, José Luís (2004). "El nuevo modelo penal de la seguridad ciudadana”. En Revista Electrónica de Ciencia Penal y Criminología (en línea) núm. 06-03, Págs. 03:1-03:34. http://criminet.ugr.es/recpc [consultado: noviembre de 2008].

DIEZ RIPOLLÉS, José Luís (2005). “De la sociedad del riesgo a la seguridad ciudadana: un debate desenfocado”. En Revista Electrónica de Ciencia Penal y Criminología (en línea) núm. 07-01, Págs. 01:1-01:37. http://criminet.ugr.es/recpc [consultado: noviembre de 2008].

DÜNKEL, F.; KESTERMANN, C.; ZOLONDEK, J. (Dir.) (2005). Estudio internacional sobre el régimen penitenciario de mujeres. Evaluación, estudio de necesidades y "mejores prácticas". Greifswald: University of Greifswald, Department of Criminology. 45 Págs.

EDGAR, K. (2007). ”Black and minority ethnic prisoners”. En Handbook on prisons. Devon: Willan Publishing. Págs. 268-292.

ESVERTIT COBES, Natalia (2008). El teixit organitzatiu d'origen equatorià a la regió de Barcelona i el seu entorn. Barcelona: Observatori de la Migració a Catalunya. 171 Págs. http://www.migracat.cat/document/73a351036b942b1.pdf [consultado: 1 de junio de 2009].

FERNÁNDEZ APARICIO, J. M. (2006). “El extranjero como delincuente y víctima”. En SepinNET, noviembre (edición electrónica). Págs. 14-26 http://clasica.sepin.es/sepinnet/visor/?referencia=sp/doct/2756 [consultado: 12 de agosto de 2009].

FERNÁNDEZ ARTIACH, Pilar (2006). El trabajo de los internos en establecimientos penitenciarios (cap. 3). Valencia: Tirant Lo Blanch. 590 Págs.

FILELLA, Gemma (1998). L'orientació ocupacional en els centres penitenciaris. Lleida: Pagès Editors. 192 Págs.

Fundación ENCUENTRO (2003a). “Inmigrantes: el reto de la integración”. En Informe España 2003. Madrid: Centro de Estudios de Cambio Social. http://www.fund-encuentro.org/informe/2003/Notas\%202003\%20pdf/00-2pIIinmi.pdf [consultado: 7 de agosto de 2008]. 
Fundación ENCUENTRO (2003b). Informe España 2003. Madrid: Centro de Estudios de Cambio Social. 468 Págs.

GARCIA ALFARAZ, A.I. (2005). “Reflexión criminológica de la inmigración”. En Revista general de derecho penal núm. 4. www.iustel.com. Noviembre 2005.

GARCIA ESPAÑA, Elisa (2001). Inmigración y delincuencia en España: análisis criminológico. Valencia: Tirant lo Blanch. 569 Págs.

GARLAND, David (2005). La cultura del control. Barcelona: Editorial Gedisa. 462 Págs.

GARRETA, J. (2008). “Familias inmigradas-escuela: proximidades y distancias”. En Cuadernos de pedagogía, núm. 380. Junio 2008. Págs. 90-95.

HAMMOND, N. (2007). “United Kingdom”. En Foreigners in European Prisons, volumen II. Págs. 809-851.

HM Prison Service (2004). Información y consejos para reclusos extranjeros. (edición electrónica) http://www.hmprisonservice.gov.uk/ assets/documents/1000109Aresource_pack_spanish.pdf [consultado: 12 de agosto de 2009].

HOFSTEE-VAN DER MEULE, F. (2007). “Treatment of foreing prisoners”. Presentación en el marco de la conferencia bianual de directores de administraciones penitenciarias organizada por el Consejo de Europa. Viena, noviembre de 2007.

HOFSTEE-VAN DER MEULE, F (2008). "Life after Prison: Resettling Adult Offenders. Resettlement of Foreign National Prisoners". Resumen de la conferencia PrisonWatch, The Netherlands Hindpal Bhui, HM Inspectorate of Prison, England and Wales. Página web de la Probation European Conference (CEP).

IBAÑEZ, J. M. (2000). Inmigración en España. Zaragoza: Editorial Combra.

IGLESIAS MACHADO, Salvador; BECERRA DOMÍNGUEZ, Miguel (2007). La inmigración: el reto del siglo XXI (Cuadernos de seguridad y policía; 5). Madrid: Dykinson.332 Págs.

IDESCAT.http://www.idescat.net/ [consultado: 2 de septiembre de 2009].

INSTITUTO NACIONAL DE ESTADÍSTICA. http://www.ine.es/inebase/cgi/axi [consultado: 2 de septiembre de 2009].

INE (2008). Estadística de condenados. Estadística de menores. Año 2007. Notas de prensa del Instituto Nacional de Estadística (INE). http: //www.ine.es/prensa/np520.pdf [consultado: 10 de diciembre de 2008].

LARIOS, M. Jesús; NADAL, Mònica (dir.) (2008). L'estat de la immigració a Catalunya. Anuari 2007. Barcelona: Fundació Jaume Bofill. Editorial Mediterrània. Págs.464.

(2005). La immigració a Catalunya avui. Anuari 2004. Págs. 452.

LEGANÉS, S. (2006). “Extranjeros en prisión”. En La ley penal núm. 30. Editorial La ley, septiembre 2006. Págs. 32-64.

London Probations (2004). Información y consejos para los reclusos extranjeros. 54 Págs.

MALGESINI, G. (comp.) (1998). Cruzando fronteras. Migraciones en el sistema mundial. Col. Economía Crítica; 14. Barcelona: Icaria. 236 Págs.

MASANET, J. M. (coord.) (2007). Manual práctico orientativo de Extranjería. Aspectos jurídicos y sociales del fenómeno de la inmigración en España. Madrid: Difusión Jurídica y Temas de Actualidad. 673 Págs.

MEDLICOTT, Diana (2007). ”Women in prison”. En Handbook on prisons. Devon: Willan Publishing. Págs. 245-267.

MONCLÚS, M. (2008). La gestión penal de la inmigración. Colección Tesis Doctoral núm. 9. Argentina: Editores del Puerto s.r.l. 544 Págs.

MORENO, R.; et al. (2008). "Consumo de drogas al ingreso en prisión: comparación entre población española y extranjera”. En Revista Española de Sanidad Penitenciaria, núm. 10. Págs. 41-47.

NACIONES UNIDAS (1984a). Recomanacions de Nacions Unides sobre el Tractament de Presos Estrangers. Comisión de las NU sobre Prevención y Control del Delito.

NACIONES UNIDAS (1984b). Acuerdo Modelo sobre el Traslado de Reclusos Extranjeros. Séptimo Congreso de Naciones Unidas sobre Prevención del Delito y Tratamiento del Delincuente.

PAJARES, M. (1999). La inmigración en España. Retos y propuestas. Barcelona: Icaria \& Antrazyt. Ministerio de Trabajo y Asuntos Socialess. 336 Págs. [Ficha 37].

PARELLA, Sònia; SABADÍ, Marc (2008). L'autoocupació de la població estrangera a Catalunya. Una aproximació quantitativa. (Informe del Observatori de la Migració a Catalunya; 9). Barcelona: Mediterrània. Págs. 269-307. http://www.migracat.cat/document/ 3111f0a3f1550b3.pdf [consultado: 1 de junio de 2009].

PASCUAL DE SANS, A. (dir.) (2002). Migracions a Catalunya: l'estat de la qüestió. Bellaterra: Servicio de publicaciones de la UAB. http: //geografia.uab.es/migracions/cat/publicacions.htm [consultado: 1 de agosto de 2008].

PEDRO DORES, Antonio (2008). Espíritu de sumisión. La justicia vista por los emigrantes. Barcelona: Anthropos. 305 Págs.

PEREZ-DIAZ, V.; ÁLVAREZ-MIRANDA, B.; CHULIÁ, E. (2004) La immigració musulmana a Europa: turcs a Alemanya, algerians a França i marroquins a Espanya. (Col. Estudis Socials; 15). Barcelona: Fundación "La Caixa”. 326 Págs.

PINYOL, G. (coord.) (2005). Cinc anys després de Tampere. II Seminari Immigració i Europa. Barcelona: Fundación CIDOB, Diputación de Barcelona. 221 Págs.

Prison Reform Trust. Prison Service United Kingdom (2002). Libro de información del recluso. Impreso por el Servicio de Publicaciones de Su Majestad. www.prisonreformtrust.org.uk [consultado: 12 de agosto de 2009].

PUIGPINOS, Rosa; et al. (2008). La salut de la població a Catalunya. El paper de la immigració. (Informe del Observatori de la migració a Catalunya; 10). Barcelona: Mediterrània. Págs. 309-338. http://www.migracat.cat/document/487dc61f234837a.pdf [consultado: 1 de junio de 2009]. 
RAMÍREZ EGAÑA, Mercedes (2007). “Sesión 8: El extranjero en prisión”. En Seminario Permanente sobre Migraciones Internacionales y Extranjería. 23 de julio de 2008. http://www.intermigra.info/intermigra/archivos/sesion8/CONCLUSIONESsesion8.pdf [consultado: 10 de agosto de 2009].

REIG, D. (coord.) (2007). Quan viatjar no és un plaer. Immigrants, exiliats, desplaçats i refugiats. Barcelona: Linguapax i Unescocat. Unitat didàctica. 56 Págs.

Reuters. "El Gobierno italiano deportará a presos extranjeros para acabar con la saturación de las cárceles”. RTVE.es Noticias (8 de septiembre de 2008). http://www.rtve.es/noticias/20080908/gobierno-italiano-deportara-presos-extranjeros-para-acabar-con-saturacion-lascarceles/152825.shtml [Consultado: 2 de marzo 2010].

RUMBAUT, R. et al. (2008). "Inmigración, encarcelamiento y delincuencia en los Estados unidos de América. La percepción pública frente a la evidencia empírica”. En Procesos de Infracción de normas y de reacción a la infracción de normas: dos tradiciones criminológicas. Madrid: Ed.Dykinson. 426 Págs.

SAMPER, Sarai; MORENO, Raquel (2009). Integració i interculturalitat: anàlisi de les trajectòries migratòries i de la integració subjectiva de la població estrangera extra comunitària a la ciutat de Barcelona. Ayuntamient de Barcelona. Dirección de Inmigración. Pág. 78. http: //www.migracat.cat/document/ [consultado: 3 de septiembre de 2009].

SAN JUAN, César; VERGARA, Anabel; OCÁRIZ, Estefania (2005). "La migración como estresor: pérdida de status, estrategias de afrontamiento e impacto psicosocial”. En Migraciones, núm. 17. Madrid: Instituto Universitario de Estudios sobre Inmigraciones, Universidad Pontificia Comillas. Págs. 91-110.

SANTIBÁÑEZ GRUBER; Rosa; MAIZTEGUI OÑATE; Concepción (ed.) (2007). Inmigración: miradas y reflejos. Historias, identidades $y$ claves de intervención social. Bilbao: Universidad de Deusto. 266 págs.

SIGUAN, Miquel (2003). Inmigración y adolescencia. Los retos de la interculturalidad. Barcelona: Paidós. 240 págs.

SOLANA SOLANA, Miguel; et al. (2002). "Migraciones en Cataluña (1975-2000) Reflexiones sobre el estado de la cuestión desde las Ciencias Sociales”. En Migraciones, núm 11. Madrid: Instituto Universitario de Estudios sobre Inmigraciones, Universidad Pontificia Comillas. Págs.141-172.

SUAREZ-OROZCO, C.; SUAREZ-OROZCO, M. (2008). Històries d'immigració: la comprensió dels patrons de rendiment escolar dels joves immigrants nouvinguts. (Col. Informes Breus; 12). Barcelona: Fundació Jaume Bofill 91 págs. http://www.fbofill.cat/intra/fbofill/ documents/publicacions/473.pdf [consultado: 16 de septiembre de 2008].

SUBIRATS, J. et al. (2009). Polítiques del càstig? Anàlisi del discurs de la política penitenciària a Dinamarca, França, Anglaterra i Gal-les i el Canadà. Barcelona: CEJFE. [Informe en pdf]. http://www.gencat.cat/justicia/cejfe.

TOURNIER, P. et al. (1997). “Au de la liberatio: observation suivi d'une cohorte d'entrants en prison”. En Études \& Données pénales núm. 76. París: Centre National de Recherche Scientifique.

UNPFA (2006). Estado de la población Mundial 2006. Hacia la esperanza: Las mujeres y la migración internacional. Fondo de Población de las Naciones Unidas. http://www.unfpa.org/upload/lib_pub_file/652_filename_sowp06-sp.pdf [consultado: 10 de agosto de 2009].

VAN KALMTHOUT, A; HOFSTEE-VAN DER MEULEN,F.; DÜNKEL, F. (2007) "Comparative overview, conclusions and recommentacions". En Foreigners in European Prisons, volumen I, Págs. 7-90.

WHEATLEY, Michael (2007). ”Drugs in prison”. En Handbook on prisons. Devon: Willan Publishing. Págs. 399-422.

ZLOVINA, Anna; BESABE, Nekane; PÁEZ, Darío (2004). “Adaptación de los inmigrantes extranjeros en España: superando el choque cultural”. En Migraciones, núm 15, Madrid: Instituto Universitario de Estudios sobre Inmigraciones, Universidad Pontificia Comillas. Págs. 43-84.

\section{Sobre los autores:}

Manel Capdevila Capdevila: es educador y pedagogo. Responsable de Investigación del Centro de Estudios Jurídicos y Formación Especializada que depende del Departament de Justícia de la Generalitat de Catalunya. También es profesor asociado en la Facultad de Educación Social y Trabajo Social de la Universidad Ramon Llull en Barcelona.

Marta Ferrer Puig: es pedagoga. Actualmente es jefa del Área de Investigación y Formación Social y Criminológica del Centro de Estudios Jurídicos y Formación Especializada. Como experta en justicia juvenil, ha formado parte durante cinco años del Consejo de Cooperación Penológica del Consejo de Europa. También ha representado al Departamento de Justicia de la Generalitat de Catalunya en el comité organizador del Forum Europeo de Justicia Restaurativa. 